\title{
Highly explosive basaltic eruptions: magma fragmentation induced by rapid crystallisation
}

\author{
F. ARZILLi ${ }^{1 *}$, G. LA SPINA ${ }^{1}$, M. R. BURTON ${ }^{1}$, M.
} POLACCI $^{1}$, N. LE GALL ${ }^{2}$, M. HARTLEY ${ }^{1}$, D. Di GENOVA ${ }^{3}$, B. $\mathrm{CAI}^{4}$, N. T. $\mathrm{VO}^{5}$, E. C. BAMBER ${ }^{1}, \mathrm{~S} . \mathrm{NONNI}^{5}, \mathrm{R}$. ATWOOD $^{5}$, E. W. LLEWELLIN ${ }^{6}$ R. A. BROOKER ${ }^{7}$, H. M. MADER $^{7}$ AND P. LEE ${ }^{2}$

${ }^{1}$ Department of Earth and Environmental Science, University of Manchester, UK $(*$ correspondence:

fabio.arzilli@manchester.ac.uk)

${ }^{2}$ Department of Mechanical Engineering, UCL, UK

${ }^{3}$ Institute of Non-Metallic Materials, Clausthal University of Technology, Germany

${ }^{4}$ School of Metallurgy and Materials, University of Birmingham, UK

${ }^{5}$ Diamond Light Source, Didcot, UK

${ }^{6}$ Department of Earth Sciences, Durham University, UK

${ }^{7}$ School of Earth Sciences, University of Bristol, Bristol, UK

The low viscosity of basaltic magmas generally favours effusive and mildly explosive volcanic activity. Highly explosive basaltic eruptions occur less frequently and their eruption mechanism still remains subject to debate, with implications for the significant hazard associated with explosive basaltic volcanism. Particularly, highly explosive eruptions require magma fragmentation, yet it is unclear how basaltic magmas can reach the fragmentation threshold.

Here we combined a bespoke high-temperature environmental cell with fast synchrotron X-ray microtomography to image the evolution of crystallization in real time. The crystallization experiments were performed in situ at Diamond Light Source (I12 beamline), Harwell, UK, using basalt from the 2001 Etna eruption as the starting material. After 4 hours at sub-liquidus conditions the system was perturbed through a rapid cooling $\left(0.4{ }^{\circ} \mathrm{C} / \mathrm{s}\right)$, inducing a sudden increase of undercooling. Our study reports the first in situ observation of exceptionally rapid plagioclase and pyroxene crystallisation in basaltic magmas. We combine these constraints on crystal kinetics and viscosity evolution with a numerical conduit model to show that pre-eruptive temperatures $<1,100^{\circ} \mathrm{C}$ and exceptionally rapid syn-eruptive crystallisation of an ascending magma under high undercooling and high decompression rates are the fundamental conditions required to trigger basaltic magma fragmentation at high strain rates. This implies that all basaltic systems on Earth have the potential to produce highly explosive and hazardous eruptions. 